\title{
Use of plastic waste in civil constructions and innovative decorative material (eco-friendly)
}

\begin{abstract}
The project elucidates about the use of plastic in civil construction. The components used include everything from plastic screws and hangers to bigger plastic parts that are used in decoration, electric wiring, flooring, wall covering and waterproofing. Plastic use in road construction that have shown same hope in terms of using plastic waste in road construction. i.e. plastic roads. Plastic roads mainly use plastic carry bags, disposable cups and PET bottles that are collected from garbage dumps as important ingredients of the construction materials. By using plastic waste as modifier, we can reduce the quantity of cement and sand by their weight, hence decreasing the overall cost of construction. At $5 \%$ optimum modifier content, strength of modified concrete we found to see the times greater than the plain cement concrete. Using plastic poisons our food chain under the plastic affects human health. By the disposable plastics is the main source of plastic. For these plastic pollution is not only the ocean also in desert. Plastic will increase the melting point of the bitumen. Rain water will not seep through because of the plastic in the tar. So, this technology will result in lesser road repairs.
\end{abstract}

Keywords: $\mathrm{M}_{2} \mathrm{O}$, plain cement concrete, waste plastic, technology, construction, rain water
Volume 3 Issue 5 - 2017

\author{
Mohammed Jalaluddin \\ Jayaprakash Narayan College of Engineering, India
}

Correspondence: Mohammed Jalaluddin, B-Tech (Civil Engineering), M.E (Transportation Engineering), Department Of Civil Engineering,, Jayaprakash Narayan College of Engineering, Mahabubnagar, India, Tel 903-095-627-8, Emailmd.jalalII3@gmail.com

Received: May 19, 2017| Published: December 04, 2017

\section{Introduction}

Nowadays, human apply all of its potentiality to consume more. The result of this high consumption is nothing unless reducing the initial resources and increasing the landfill. In recent times, human from the one hand is always seeking broader sources with lower price and from the other hand is following the way to get rid of the wastes. The waste today can be produced wherever humans footprints be existed, and remind him that they have not chosen the appropriate method for exploitation of the nature. This paper introduces the development and low cost housing in India. At the present time, the possibility of utilizing the renewable resources such as solar, geothermal has been provided for us more than before, and development of the renewable and alternative energies is making progress. Plastic have become an essential part of our day to day life since their introduction over hundred years ago. The only way to reduce the hazards of plastic is reduce and reuse (Figure1).

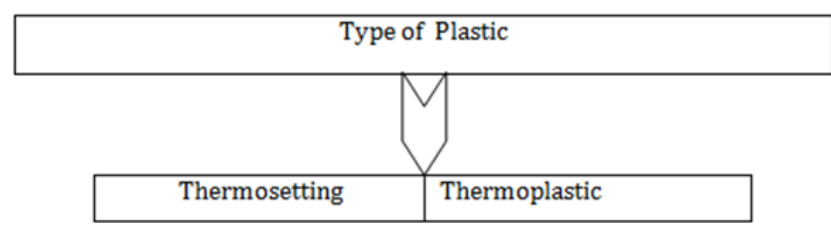

Figure I Types of plastic.

\section{Pet plastic}

\section{Introduction of PET}

PET is used for high impact resistant container for packaging of soda, edible oils and Peanut butter (Table 1). Used for cereal box liners, Microwave food trays. Used in medicine for plastic vessels and for Implantation. Plastic is heat resistant and chemically stable. PET is resistant to acid, base, some solvents, oils, fats. PET is difficult to melt and transparent and other properties are Table 2.

Table I Properties of plastic

\begin{tabular}{ll}
\hline Full Form & Polyethylene terephthalate \\
\hline Molecular formula & $\mathrm{C}_{10} \mathrm{H}_{8} \mathrm{O}_{4}$ \\
Structure Composition & $\begin{array}{l}\text { Polyester of Terephthalic acid and } \\
\text { ethylene glycol }\end{array}$ \\
\hline
\end{tabular}

Table 2 Properties of soil

\begin{tabular}{ll}
\hline Soil particle & Diameter $(\mathbf{m m})$ \\
\hline Gravel & $>2.0$ \\
Sand & $0.05-2.0$ \\
Silt & $0.002-0.05$ \\
Clay & $<0.002$ \\
\hline
\end{tabular}

\section{Properties of plastic}

Plastic have many good characteristics which include versatility, light-ness, hardness, and resistant to chemicals, water and impact. Plastic is one of the most disposable materials in the modern world. It makes up much of the street side litter in urban and rural areas. It is rapidly filling up landfills as choking water bodies. Plastic bottles make up approximately $11 \%$ of the content landfills, causing serious environmental consequences.

Due to the consequences some of the plastic facts are as follow:

1. More than 20,000 plastic bottles are needed to obtain one ton of plastic. 
2. It is estimated that 100 million tons of plastic are produced each year.

3. The average European throws away $36 \mathrm{~kg}$. of plastics each year.

4. Some plastic waste sacks are made from $64 \%$ recycled plastic.

5. Plastics packaging totals $42 \%$ of total consumption and every year little of this is recycled. According to ENSO Bottles, in the 1960 's plastic bottle production has been negligible but over the years there was an alarming increase in bottles produced and sold but the rate of recycling is still very low.

Plastics are produced from the oil that is considered as nonrenewable resource. Because plastic has the insolubility about 300 years in the nature, it is considered as a sustainable waste and environmental pollutant. So reusing or recycling of it can be effectual in mitigation of environmental impacts relating to it. It has been proven that the use of plastic bottles as innovative materials for building can be a proper solution for replacement of conventional materials. The use of this material has been considered not only for exterior walls but also for the ceiling of the building. The objective of this paper is to investigate the key and positive characteristics of this product and the benefits obtained by using it in building. It also intends to compare the characteristics of some construction materials such as brick, ceramic and concrete block with bottle. One can use solar bomb (bottle filled with bleaching powder solution) will be fitted on the roof for light source (Figure 2).

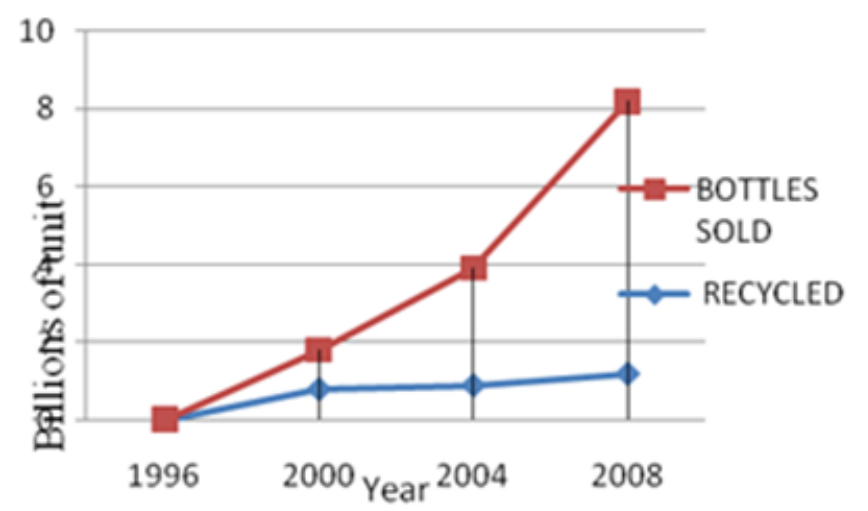

Figure 2 PET bottle sales/recycled.

\section{Chapter-2: Disadvantages of plastic bottles Introduction}

Plastic bottles are certainly ubiquitous they bring us everything from house hold cleaners to soft dryings to things so readily available as water these bottles, while convenient, do have disadvantages when used on as wide a scale while most of these disadvantages are environmental in nature the consequences could have widespread economical consequences in the long-term.

\section{Disadvantages of plastic bottles}
I. Decomposition
II. Non Renewable
III. Hard To Use
IV. Difficult To Recycle

Decomposition: The main disadvantages of plastic bottles is the shear amount of time they take to decompose he averages plastic bottle takes 500 years plastics decomposition can be agented by various factors, such as the types of plastic, the climate and acids in the landfill; plastic still lasts a long time, filling landfills for an indefinite period.

Non-renewable: Plastic is manufactured using oil by products and natural gas material that could be used in numerous other applications or conserved was plastic usage lower. Natural gas for example, can be used to heat houses and cook food. Using plastic in the volume we currently do reduces the availability of these resources, which are gone forever when used up.

Hard to use: The standard disposable plastic bottle is meant for one use, not many. Recycled plastic bottles are not refilled in mass they glass beer bottles are, and flimsy plastic bottles do not lead themselves well to at home re-usage. Water bottles, for example, are often reused in the home but become less and less sturdy over time and are ultimately thrown away.

Difficult to recycle: Glass bottles can be meted and easily reused as can tin cans. Recycling plastic is not so simple. Much of the plastic placed in recycling boxes is not recycled at all, as most plastic cannot be recycled those bottles that are recycled are not used to make new bottles. Instead recycled plastic bottles are used to make nonrecyclable products, such as t-shirts, lactic lumber or parking lot bummers. This means more raw materials need to be used to create new plastic bottles than is the case with easily recycled material, such as glass or tin.

\section{Chapter-3: Basic construction materials and properties}

\section{Introduction}

This construction require some of the basic materials which ensures a stable, eco-friendly structure and also results in cheap construction as compared to brick wall. Materials uses for Bottle wall masonry construction are:
a. Soil
b. Plastic bottles
c. Cement
d. Nylon rope
e. Water

Soil: Soil is the basic element in any construction project so before using it in our project we have to study the basic properties of the soil and go through different tests, so as to check whether the soil sample selected is suitable for the given project (Table 2).

Soil texture: Soil texture can have a profound effect on many other properties and is considered among the most important physical properties. Texture is the proportion of three mineral particles, sand, silt and clay, in a soil. These particles are distinguished by size, and make up the fine mineral fraction.

Soil colloids: Soil colloids refer to the finest clay in a soil. Colloids are an important soil fraction due to properties that make them the location of most physical and chemical activity in the soil. One such property is their large surface area. Smaller particles have more surface area for 
a given volume or mass of particles than larger particles. Thus, there is increased contact with other colloids and with the soil solution. This results in the formation of strong friction and cohesive bonds between colloid particles and soil water, and is why a clay soil holds together better than a sandy soil when wet.

Soil structure: Soil structure is the arrangement and binding together of soil particles into larger clusters, called aggregates or pads. Aggregation is important for increasing stability against erosion, for maintaining porosity and soil water movement, and for improving fertility and carbon sequestration in the soil. Granular structure consists of loosely packed spherical pads that are glued together mostly by organic substances.

Soil porosity: Many important soil processes take place in soil pores (air or water-filled spaces between particles). Soil texture and structure influence porosity by determining the size, number and interconnection of pores. Coarse textured soils have many large (macro) pores because of the loose arrangement of larger particles with one another. Fine-textured soils are more tightly arranged and have more small (micro) pores. Macro pores in fine textured soils exist between aggregates. Because fine-textured soils have both macro- and micro pores, they generally have a greater total porosity, or sum of all pores, than coarse-textured soils.

Plastic bottle: In this paper plastic bottles are used as a fundamental element, so we have gone through every property of the PETE bottles so as to ensure a stable structure.

Properties of pete bottle: Polyethylene Terephthalate Ethylene (PETE) bottles are thermoplastic materials. This type of plastic are polymers and with or without cross linking and branching, and they soften on the application of heat, with or without pressure and require cooling to be set to a shape. Following are properties of plastic bottle:

a. Wax like in appearance, translucent, odorless and one of the lightest plastics.

b. Flexible over a wide temperature.

c. Heat resistance.

d. Chemically stable.

e. Do not absorb moisture

f. Transparent.

Cement: Cement is the important binding material. In these paper it is use to bind the plastic bottles to make the masonry wall more durable so that the quality of cement is check by following properties.

\section{Properties of cement}

Fineness: Fineness or particle size of Portland cement affects Hydration rate and thus the rate of strength gain. The smaller particle size, and the greater the surface area-to-volume ratio so that the more area available for water cement interaction per unit volume. The effects of greater fineness on strength are generally seen during the first seven days.

Soundness: Soundness is defined as the volume stability of the cement paste.

Strength: Cement paste strength is typically defined in three ways: compressive, tensile and flexural. These strengths can be affected by a number of items including: water cement ratio, cement-fine aggregate ratio, type and grading of fine aggregate, curing conditions, size and shape of specimen, loading conditions and age.

Setting Time: The initial setting time is defined as the length of time between the penetration of the paste and the time when the needle penetrates $25 \mathrm{~mm}$ into the cement paste.

Nylon rope: Nylon rope has a very high tensile strength so that it is use as the main binder for PETE bottles masonry.

Properties of nylon Rope: Nylon rope is gotten from coal, Petroleum, air and water. It is a polyamide thermoplastic produced by series of condensation reaction between an amine and organic acids. the properties of nylon as follow:

a. Good abrasion resistance.

b. Tough and strong but flexible too.

c. High impact strength.

d. Absorb water which causes reduction in strength and impact properties

e. Resistant to most of the solvents and chemicals

f. High softening temperatures and thus molding becomes difficult.

Water: Water is in a similar way like cement, an active component in mortar. For cement-sand mortar, without water no hydration can be attained, hence no strength can be achieved. Water is responsible for the workability of a fresh mortar. $20 \%$ of the overall weight of the cement and soil was used to determine the quantity of water to be used in the mix. A slump test and a flow test were conducted to evaluate the consistency of the fresh mortar.

\section{Chataper-4: Literature review}

Mojtaba et al., ${ }^{1}$ Concluded that reusing the plastic bottles as the building materials can have substantial effects on saving the building embodied energy by using them instead of bricks in walls and reducing the $\mathrm{CO}_{2}$ emission in manufacturing the cement by reducing the percentage of cement used. It is counted as one of the foundation's green project and has caught the attention of the architecture and construction industry. Generally the bottle houses are bioclimatic in design, which means that when it is cold outside is warm inside and when it is warm it is cold inside. Constructing a house by plastic bottles used for the walls, joist ceiling and concrete column offers us $45 \%$ diminution in the final cost. Separation of various components of cost shows that the use of local manpower in making bottle panels can lead to cost reduction up to $75 \%$ compared to building the walls using the brick and concrete block.

Shilpi et al., ${ }^{2}$ concluded that by utilizing PET bottles in construction recycled materials, thermal comfort can be achieved in very low cost housing, benefit in residents for those who cannot afford to buy and operate heating and cooling systems. Plastic is non-biodegradable, toxic, highly resistant to heat and electricity (best insulator) and not recyclable in true sense, plastic PET bottles use in bottle brick technique. This gives relief for the poor people of India to provide cheap and best houses for living. ${ }^{3-5}$

Puttaraj et al., ${ }^{6}$ examined that efficient usage of waste plastic in plastic-soil bricks has resulted in effective usage of plastic waste and thereby can solve the problem of safe disposal of plastics, also avoids 
its widespread littering and the utilization of quarry waste has reduced to some extent the problem of its disposal. Plastics are produced from the oil that is considered as non-renewable resource. Because plastic has the insolubility about 300 years in the nature, it is considered as a sustainable waste and environmental pollutant. So reusing or recycling of it can be effectual in mitigation of environmental impacts relating to it. It has been proven that the use of plastic bottles as innovative materials for building can be a proper solution for replacement of conventional materials. ${ }^{4}$

Pratima et al., ${ }^{7}$ studied that plastic bottles wall have been less costly as compare to bricks and also they provide greater strength than bricks. The PET bottles that are not recycled end up in landfills or as litter, and they take approximately 1000 years to biodegrade. This has resulted in plastic pollution problems in landfills, water ways and on the roadside, and this problem continues to grow along with the plastic bottle industry.

Arulmalar et al., ${ }^{8}$ studied that the initial perception on the use of PET bottles in construction is changing day by day. A paradigm which emerged as PET bottle bricks in the construction of load bearing walls with steel trusses and prefabricated metal sheet is at present witnessing flat roofs with nylon 6 replacing steel reinforcement and intuitive vault construction. ${ }^{6}$ Even though research on the effective use PET in developing new material as an option, solutions exploring the application of PET bottles as structural members, foundation, retaining walls and secondary elements like street furniture, road dividers, pavements and other landscape elements is to be looked in to. The Governing bodies shall formulate policies to propagate this eco centric approach via appropriate practices, research investigations on the properties of the materials and construction techniques.

Vikram Pakrashi et al., ${ }^{9}$ examined Eco-brick is a viable resource for construction purposes with a number of possible applications. The bricks are relatively easily manufactured with controlled weight and packing. Eco bricks have relatively good compressive strength, with values matching that of basic concrete cubes. The weight of Ecobrick was observed to hold a nearly relationship with load at failure and with specific strength. Eco-bricks have a relatively good specific strength. They are lightweight but strong for the weight they bear.

Andreas Froese et al. ${ }^{10}$ concluded that when the bottles are filled with soil or sand they work as bricks and form a framework for walls or pillars. Different types of walls varying in size and orientation of the bottles are built. The compression strength and fracture behavior of each wall are measured and compared. PET bottle walls can bear up to $4.3 \mathrm{~N} / \mathrm{mm}^{2}$ when the bottles are filled with sand which is the weakest filling material. The bottles bear one third of the load while the plaster bears two thirds. Plaster made of clay or a cement mixture fills the space between all bottles while a roof made of wood or corrugated metal completes the house. As only regional products are used the houses are cheap and can be afforded even by poor families. Additionally the method has so far proven to be earthquake resistant and allows short construction periods.

Yahaya Ahmade et al., ${ }^{11}$ said that the structure has the added advantage of being fire proof, bullet proof and earthquake resistant, with the interior maintaining a constant temperature of 18 degrees $\mathrm{C}$ (64 degrees F) which is good for tropical climate.

Seltzer et al., ${ }^{12}$ revealed that the first example of known structures built with bottles is the William F. Peck's Bottle House located in Nevada (USA). It was built around 1902, and it required 10,000 beer bottles to be built. These buildings were primarily made out of glass bottles used as masonry units and they were bound using mortar made out of adobe, sand, cement, clay and plaster.

Job Bwire \& Arithea Nakiwala et al., ${ }^{13}$ suggested that, baked bricks, tiles, concrete and rocks, among other construction materials, have been essentials in construction. But did you know that a house constructed using plastic bottles can save you more and be just as strong as or even stronger than brick homes? Water bottle housing is an innovation aimed at providing low cost housing, while contributing to environment management. ${ }^{14-18}$

\section{Chapter-5}

\section{Background}

Introduction: The first bottle house was constructed in 1902 by William F.Peck in Tonopah; Nevda. The house was built with 10,000 bottles of beer, which were $90 \%$ alcohol and $10 \%$ opium. The Peck house was demolished in the early 1980's. The use of empty vessels in construction dates back to ancient Rome, which had structures with amphorae embedded in concrete. This was not done for aesthetic reasons, but to lighten the load of upper levels of structures empty, and to reduce concrete usage. The first plastic bottle construction project in Africa was pioneered in Uganda by Butakoola Village Association for Development (BUVAD) in 2010 in Cayuga district. The idea followed a BUVAD community survey in 2009 that revealed that many farmers in Kayunga were experiencing low crop yields due to poor soil fertility, which was a result of the presence of waste plastics, such as bottles and polythene bags, in the soil (Figure 3). Dec 2nd, 2010 proving that there are all kinds of uses for recycled PET plastic, Taiwan-based Er. Arthur Huang processed 1.8 million used plastic bottles into honey comb-shaped bricks for a boat-shaped exhibition hall called the Eco-ARK. Built for Taipei's flower show, Eco-ARK was constructed for just one-third the cost of a conventional structure. Once locked together, the bricks are extremely strong (Figure 4). May 2011 Samarpan Foundation has constructed a children school in New Delhi, using hundreds of used PET bottles instead of conventional bricks (Figure $5 \& 6$ ).

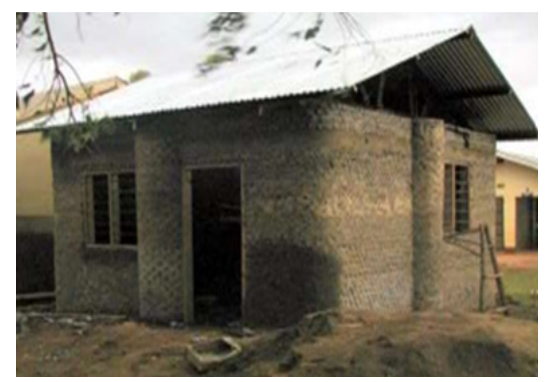

Figure 3 First bottle house construction.

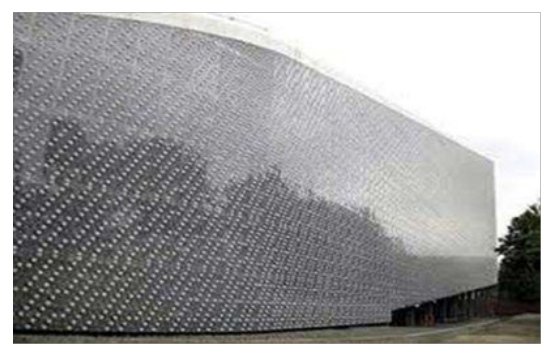

Figure 4 Eco-ARC built for taipei's. 


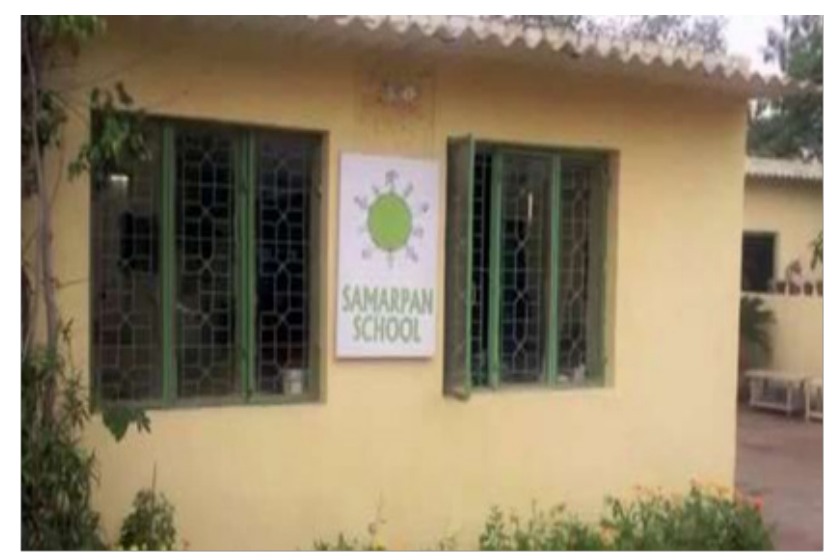

Figure 5 Samarpan foundation.

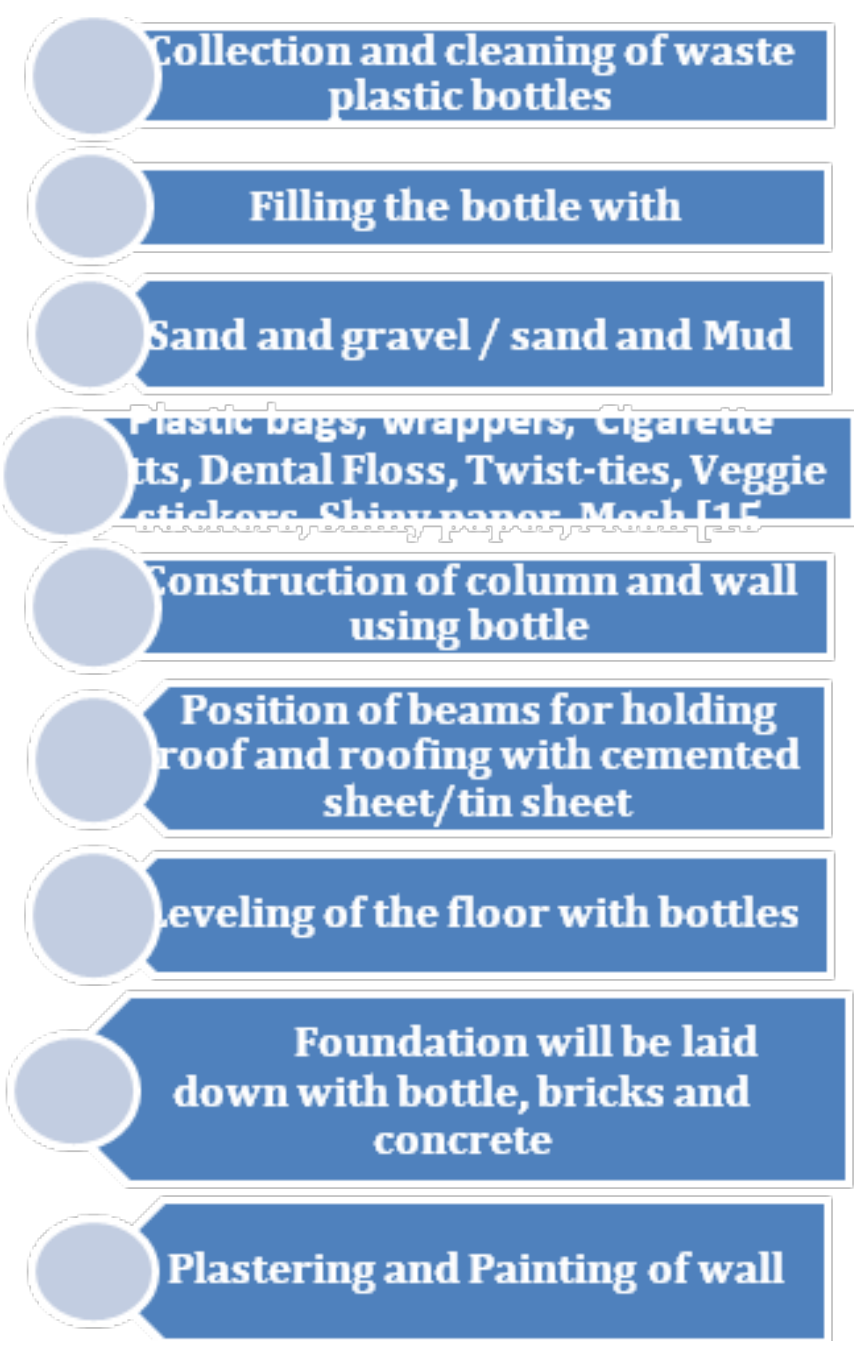

Figure 6 Methodology for construction of plastic bottle House.

Chapter-6: Mortar calculation

No. of labour calculation: One labour can made 400 bottles per day (filling soil in bottles) (Table 3).
Total no. of bottles $=157$.

Numbers of labour needed $=(1572 / 400)=4$ nos $($ Table 4$)$. 
Table 3 Cost estimation of brick wall masonry

\begin{tabular}{llllll}
\hline S. no & Material & Quantity & Rate & Per & Amount(Rs.) \\
\hline I & Brick & I I 50 nos. & 5 & I no. & 5750 \\
2 & Cement & 5.45 & 300 & I bag & 1635 \\
3 & Sand & 0.237 & 250 & I m3 & 59.25 \\
Total & - & - & - & - & 7444.25
\end{tabular}

Table 4 Cost estimation of plastic bottle wall

\begin{tabular}{llllll}
\hline S. no & Material & Quantity & Rate & Per & Amount(Rs.) \\
\hline I & Plastic bottle & I 572 nos. & 0.5 & I no. & 786 \\
2 & Cement & 5.45 & 300 & I bag & 1635 \\
3 & Sand & 0.237 & 250 & Im3 & 59.25 \\
4 & Soil & 1.99 & 100 & Im3 & 199 \\
5 & Labour work & 4 & 300 & I person & 1200 \\
Total & - & - & - & - & 3879.25 \\
\hline
\end{tabular}

Comparison between the walls by plastic bottle wall and brick wall: For construction Time and speed of Execution for 5 persons team-one working day for plastic wall is $15 \%$ faster and for brick wall $120 \mathrm{~m}^{2}$. Material and equipment cost for plastic bottle wall is less as compared to brick wall. Transportation cost for plastic bottle wall Table 5 Comparison between the wall by plastic bottle and brick construction is less than brick wall. Plastic bottle wall construction require less manpower as compare to brick wall and require high cost. Strength and load capacity for plastic bottle wall construction is 20 times more than brick wall construction (Table 5).

\begin{tabular}{|c|c|c|c|c|}
\hline S. No & Factors & Considerations & Plastic bottle wall & Brick wall \\
\hline I & $\begin{array}{l}\text { Time and speed of } \\
\text { Execution }\end{array}$ & 5 persons team one working day & $15 \%$ faster & $120 \mathrm{~m} 2$ \\
\hline 2 & $\begin{array}{l}\text { Material and equipment } \\
\text { costs }\end{array}$ & $\begin{array}{l}\text { Implementation and installation of } \\
\text { materials and equipment }\end{array}$ & $\begin{array}{l}\text { Saving in cement, water, } \\
\text { grinder and fitting }\end{array}$ & More weight, more materials \\
\hline 3 & Transportation Costs & Displacement in the building & $\begin{array}{l}\text { Lighter and higher volume, } \\
\text { easy and cheap displacement }\end{array}$ & $\begin{array}{l}\text { Greater weight and less volume, hard } \\
\text { and costly displacement }\end{array}$ \\
\hline 4 & Execution cost & Using calculations of panel & $\begin{array}{l}\text { Less manpower and } \\
\text { indigenous }\end{array}$ & $\begin{array}{l}\text { More human resources- the higher } \\
\text { cost }\end{array}$ \\
\hline 5 & $\begin{array}{l}\text { Strength and load } \\
\text { Capacity }\end{array}$ & - & 20 times more than brick & $\begin{array}{l}\text { Greater wall thickness, lower strength } \\
\text { High weight and loss of material }\end{array}$ \\
\hline 6 & $\begin{array}{l}\text { Resistance to } \\
\text { Earthquake }\end{array}$ & $\begin{array}{l}\text { Earthquake has a direct relationship } \\
\text { with the weight of each structure }\end{array}$ & $\begin{array}{l}\text { Low and Integrated weight } \\
\text { without falling debris }\end{array}$ & - \\
\hline 7 & $\begin{array}{l}\text { Cleanness and beauty } \\
\text { of work }\end{array}$ & - & $\begin{array}{l}\text { Very clean execution, no } \\
\text { construction waste }\end{array}$ & High volume of construction waste \\
\hline 8 & Flexibility & - & $\begin{array}{l}\text { Very clean execution, no } \\
\text { construction waste }\end{array}$ & - \\
\hline
\end{tabular}

Chapter-7: Benefits of plastic bottle masonry wall

The most important benefits of these alternative innovative materials compared to conventional materials such as brick can include:

\section{Good construction ability}

The walls built by these bottles are lighter than the walls built by brick and block, and that makes these buildings to show a good response against earthquake. Due to the compaction of filling materials in each bottle, resistance of each bottle against the load 
is 20 times higher compared to brick. And these compressed filling materials, makes the plastic bottle to be prevented from passing the shot that makes the building as a bulletproof shelter.

\section{Low cost}

Constructing a house by plastic bottles used for the walls, joist ceiling and concrete column offers us $45 \%$ diminution in the final cost. Separation of various components of cost shows that the use of local manpower in making bottle walls can lead to cost reduction up to $75 \%$ compared to building the walls using the brick and concrete block. It must be noted that the sophisticated manpower can lead to reducing the construction time and the relative costs also become lower.

\section{Non-britte characteristics}

Using the non-brittle materials can reduce construction waste. Unlike brick, plastic bottle is non-brittle. So due to the frangibility property, the percentage of producing construction waste in brick is more than plastic bottles.

\section{Absorbs abrupt shock loads}

Flexibility is a characteristic which makes the buildings performance higher against the unexpected load. Since the plastic bottles are not fragile, they can be flexible and tolerates sudden loads without failure. This characteristic can also increase the buildings bearing capacity against the earthquake.

\section{Green construction}

Plastic bottles can cause the green construction by saving energy and resources, recycling materials, minimizing the emission, having significant operational savings and increasing work place productivity. These 13 plastic bottle vertical garden ideas will interest you if you are a creative person, DIY lover and love to grow plants. This way you can use plastic bottles to make something amazing out of them. Repurpose those old bottles, which you usually throw away to grow your favorite plants either indoor or outdoor and help to save our environment (Figure 7). If you love DIY ideas and you have a green thumb then starting a window farm is a smart idea. A window farm will let you do a lot with the little amount of space you have. The indoor windowfarms (Figure 8). Fallows the crops to take full advantage of the light and vertical space available at the windows. Here in this PDF, you will find all the instructions on how to build a Window Farm. Follow this amazing idea for growing small leafy vegetables, such as lettuce, fenugreek and spinach, herbs and medicinal plants. This plastic bottle vertical garden is made of by stringing the bottles horizontally in a grid along an interior wall, which then filled up by substrate and herbs (Figure 9). A remarkable kitchen garden with plastic bottles with minimal means and efforts. It can be set up easily and does not require regular watering. Here is the tutorial with more images of it (Figure 10). Do you want to create a low maintenance vertical soda bottle garden? Follow this idea. All that is required is bottles cut in half, cactus plants or succulents, and many colorful threads to get a really cool decorative effect (Figure 11). Use two-liter soda bottles, cut them in half and use the neck side. Turn them upside down. Adhere the bottles to a wooden frame and arrange them in such a way so that the open neck of the bottle will drain out the water into the bottle below it (Figure 12). Here's an another idea to create a vertical garden using the plastic bottles. It is a great way to reuse old plastic bottles and to introduce some greenery to a small urban space (Figure 13). One more wonderful idea to make use of plastic bottles, more useful if you don't have much space on the ground (Figure 14). A hanging plastic bottle garden to make full use of vertical space. In this post, which we found on Source: Container Gardening (Figure15). Plastic bottles are mounted on the wall for utilizing the vertical space. Bushy and trailing plants like lettuces and strawberries hide the structure, creating a nice 'green wall' effect (Figure 16). Another innovative and great looking plastic bottle vertical garden. Bottles are hanging horizontally, attached through the strings (Figures $17 \& 18$ ). Want to grow herbs but you don't have space? Well, even a wooden plank is enough. All you need is some plastic bottles, hooks, nails and hammer and you're all set to grow your own herbs. Be sure to check out our post on balcony herb garden ideas to find out more ideas like that (Figures $19 \& 20$ ).

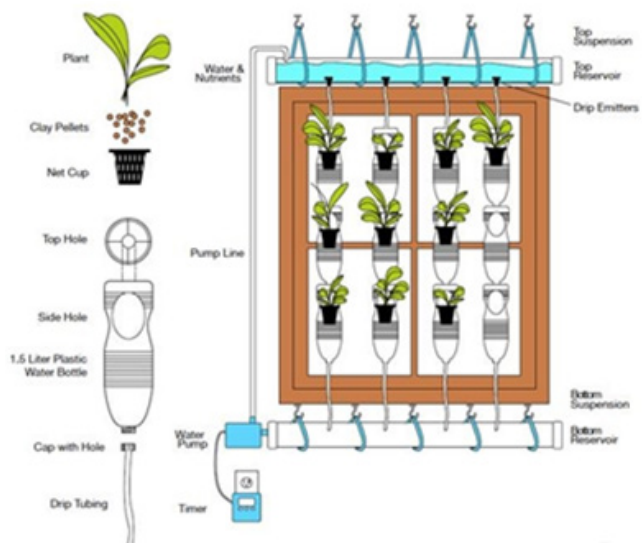

Figure 7 Window farm

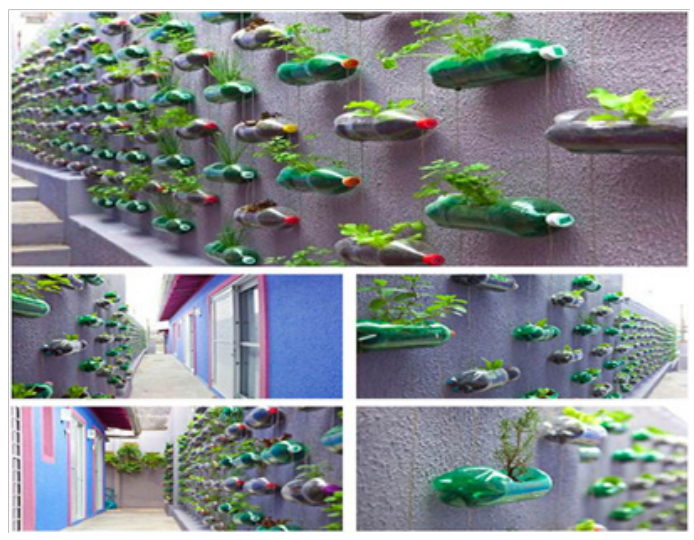

Figure 8 Plastic bottles on walls.

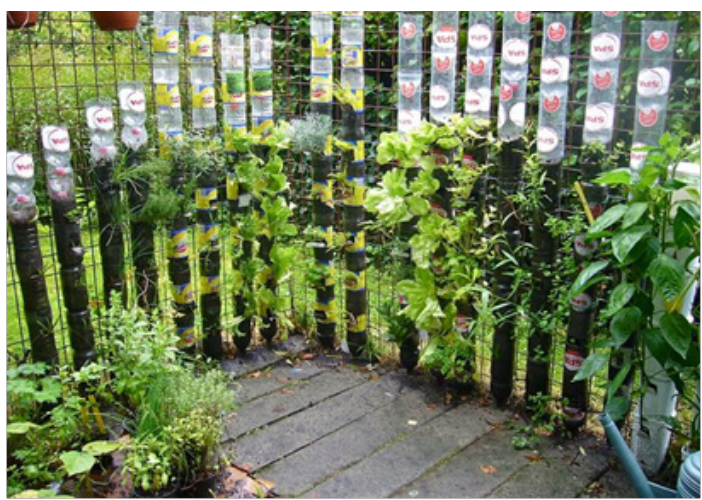

Figure 9 Plastic bottle tower garden. 


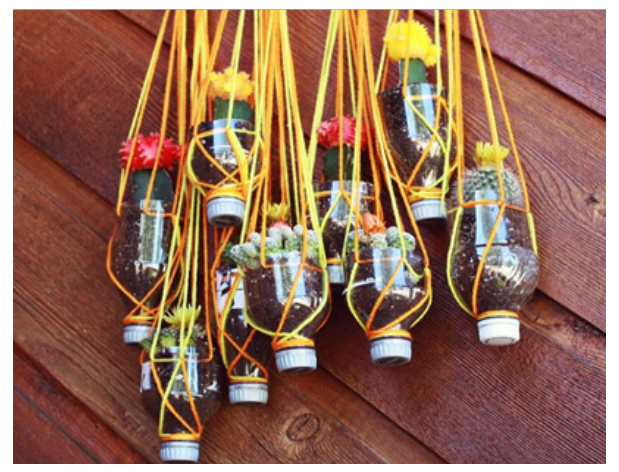

Figure 10 Growing cactus in hanging plastic bottles.

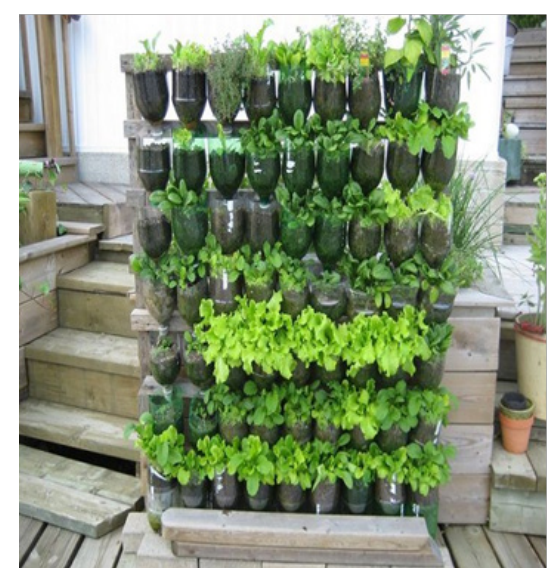

Figure II Half plastic bottle vertical garden on wooden frame.

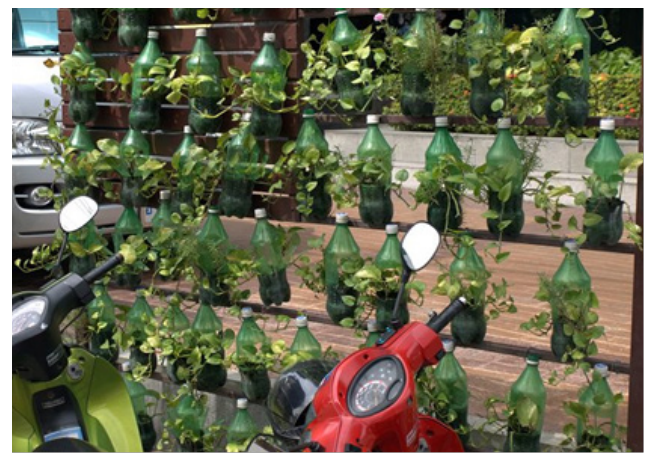

Figure 12 Here's an another idea to create a vertical garden using the plastic bottles.

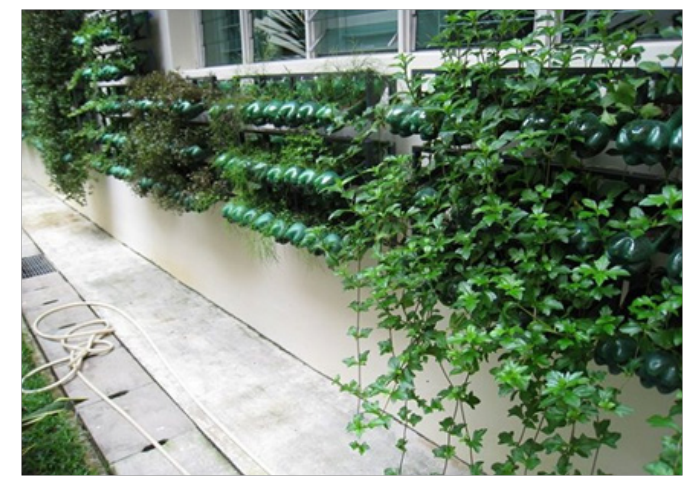

Figure 13 Another vertical garden.

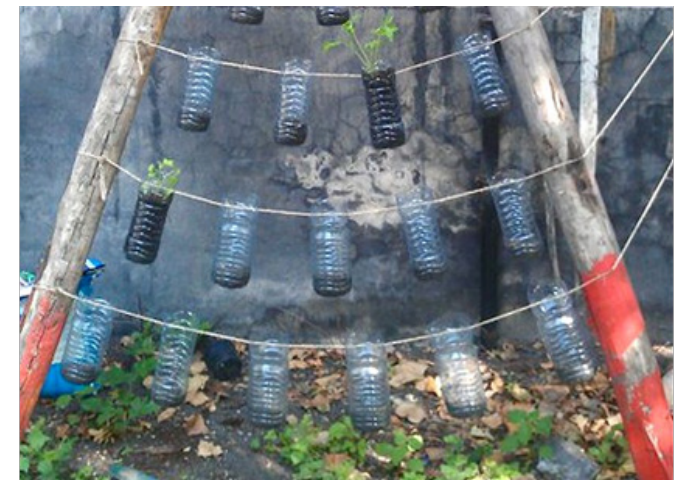

Figure I 4 Bottles hanging on string.

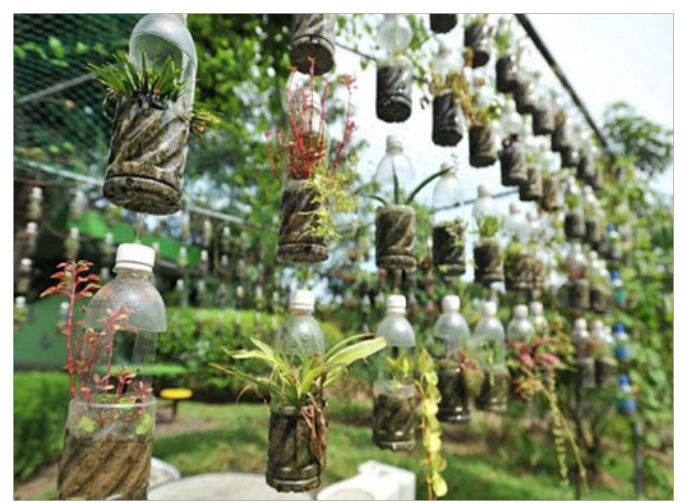

Figure 15 Plastic bottles hanging on net.

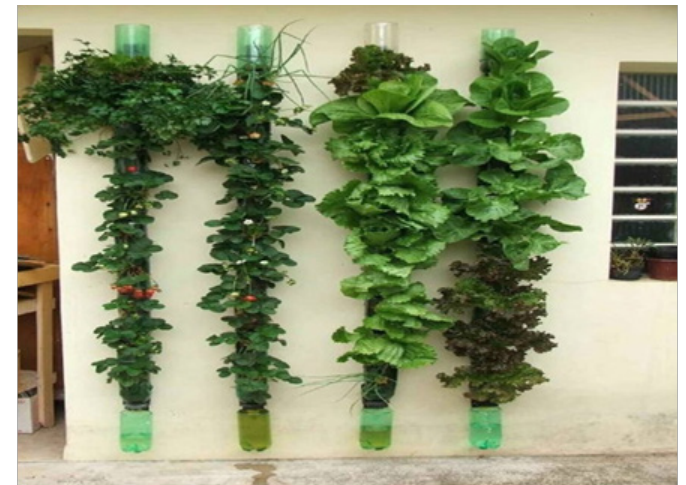

Figure 16 Inspiring plastic bottle garden.

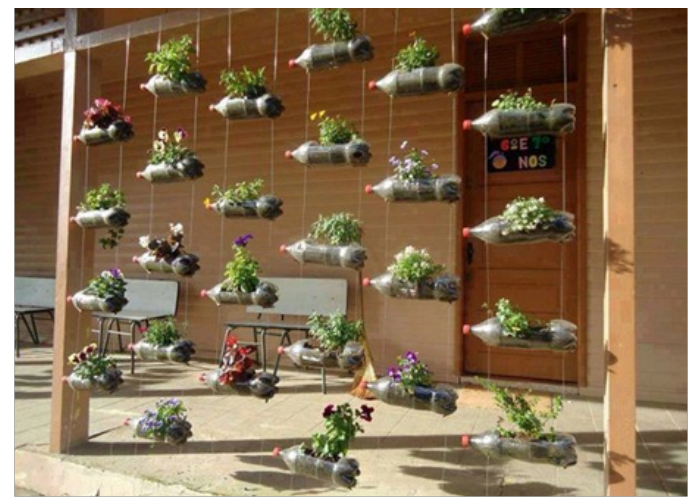

Figure 17 Hanging soda bottle garden. 


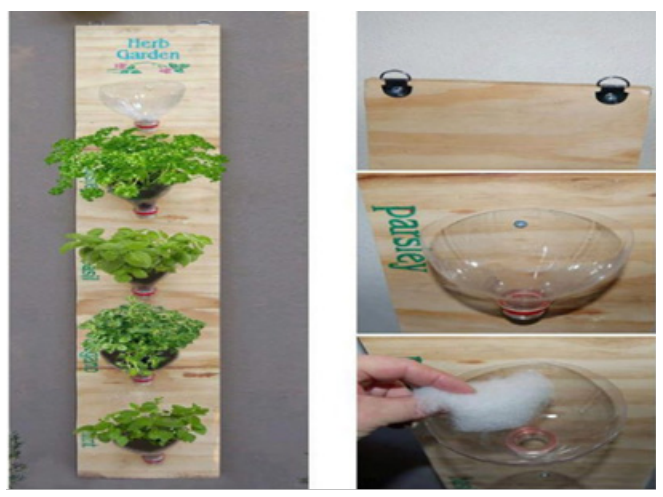

Figure 18 Vertical plastic bottle herb garden.

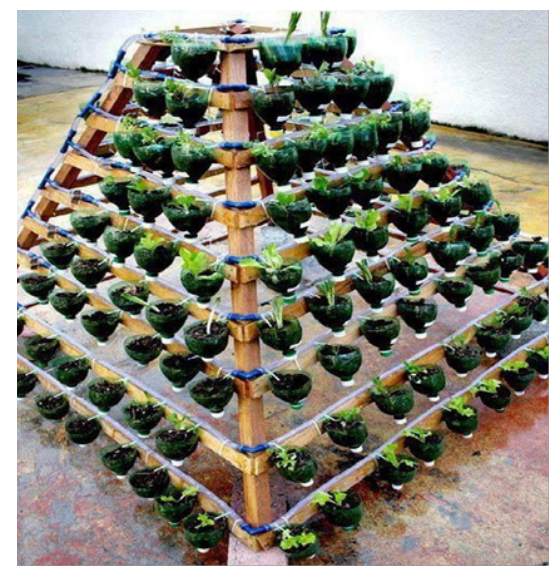

Figure 19 Pyramid plastic bottle garden.

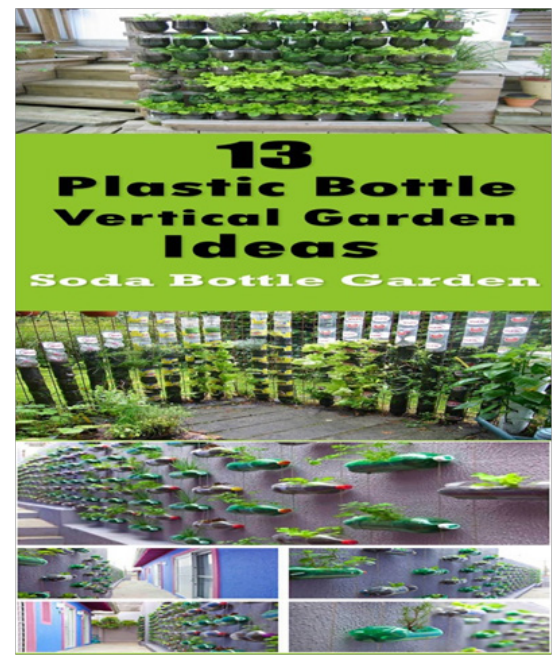

Figure $20 \mathrm{~A}$ vertical pyramid garden made of plastic bottles.

\section{Chapter-8: Conclusion}

a. Use of innovative materials with sustainable application such as plastic bottles can have considerable benefits including finding the best optimization in energy consumption of the region, reducing environmental degradation.

b. Generally the bottle houses are bio-climatic in design, which means that when it is cold outside is warm inside and vice versa. c. Re-using the plastic bottles as the building materials can have substantial effects on saving the building embodied energy by using them instead of bricks in walls and reducing the $\mathrm{CO}_{2}$ emission in manufacturing the cement by reducing the percentage of cement used.

d. Plastic bottles can cause the green construction by saving energy and resources, recycling materials, minimizing the emission, having significant operational savings and increasing work place productivity.

e. Cost compression between bottles wall is roughly half than conventional brick masonry. i.e., Total cost of $10 \mathrm{~m} 2$ Brick masonry wall is Rs. 7444.25 and total cost of $10 \mathrm{~m} 2$ Bottle masonry wall is Rs. 3879.2

f. Use of innovative materials with sustainable application such as plastic bottles can have considerable benefits including finding the best optimization in energy consumption of the region, reducing environmental degradation.

g. Plastic bottles can cause the green construction by saving energy and resources, recycling materials, minimizing the emission, having significant operational savings and increasing work place productivity (Figure 21).

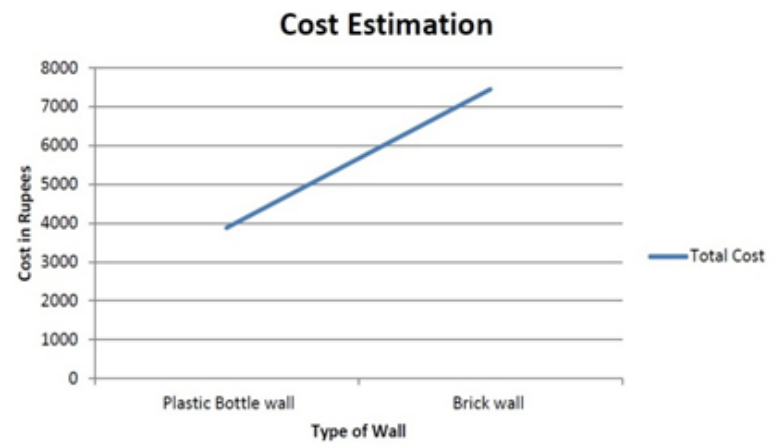

Figure 2I Graph between Cost in Rupees and total Cost.

\section{Acknowledgments}

None.

\section{Conflicts of interest}

Author declares that there is no conflict of interest.

\section{References}

1. Mojtaba VS, Azin SB. Investigating the Application of Plastic Bottle as a Sustainable Material in the Building Construction. International Journal of Science, Engineering and Technology Research (IJSETR). 2013;2(1):2278-7798.

2. Shilpi S, Monika S. Eco-Architecture: PET Bottle Houses. International Journal of Scientific Engineering and Technology. 2013;2(12):1243-1246.

3. Ramadevi K. Experimental Investigation on the Properties of Concrete With Plastic PET (Bottle) Fibers as Fine Aggregates. International Journal of Emerging Technology and Advanced Engineering. 2012;2(6):1-5.

4. Samarpan foundation. House construction with plastic bottles. New Delhi, India.

5. How-To Make a Bottle Brick. 
6. Puttaraj MH, Shanmukha S. Utilization of Waste Plastic In Manufacturing of Plastic-Soil Bricks, International Journal of Technology Enhancements and Emerging Engineering Research. 2014;2(4):2347-4289.

7. Pratima P, Akash S. Sub stainable development using waste PET bottles as construction element; 2014.

8. Arulmalar R, Jothilakshmy N. 30th International Plea Conference, CEPT University: Ahmedabad, India; 2014.

9. Vikram P. Experimental Characterization of Polyethylene Terephthalate 1 (PET). Bottle Eco-Bricks. 2014;60:50-56.

10. Andreas F. Plastic bottles in construction who is the founder of ECOTEC; 2001.

11. Yahaya A. Development Association for Renewable Energies, Nigeria; 2015.
12. Seltzer DJ. Bottle houses; 2000.

13. Job B, Arithea N. Cut costs with a plastic bottle house, New Vision; 2013.

14. The sandglass construction material, www.Throughthesandglass.typepad. com.

15. Rajputa RK. Engineering materials: including construction materials. 3rd ed. S Chand \& company: New York, USA; 2007.

16. Jayaprakash K. Treasure from the trash. Indian Express: India; 2008.

17. Jayaprakash K. News Article of Indian express: Treasure from the trash, India $; 2008$.

18. Lauren Vork. How to Build a Plastic Bottle Wall, How Contributor. 